NOTES AND MEMORANDA

\title{
THE DEMAND-SUPPLY THEORY OF INCOMES TESTED BY 1970 CENSUS FIGURES
}

\author{
BY JAN TINBERGEN \\ Erasmus University, Rotterdam
}

\section{Two Simple Versions OF THE THEORY}

On another occasion [3] I presented a demand-supply theory of incomes in two versions, to be called the more complete and the reduced forms respectively. Let $x_{i}$ be employment of labour category $i ; p_{i}$ its price or income; $s_{i}$ a supply and $d_{i}$ a demand factor (all measured by their logarithms). The more complete version of the theory will be written (Version II):

$$
\begin{aligned}
& x_{i}=\alpha_{1} s_{i}+\alpha_{2} p_{i} \\
& x_{i}=\beta_{1} d_{i}-\beta_{2} p_{i}
\end{aligned}
$$

where (1) is the supply and (2) the demand equation. The supply factor $s_{i}$ may be the (logarithm of the) number of persons with qualification $i$ and the demand factor the (logarithm of the) number of such people the employers would wish to employ if some "normal" situation prevails. As usual, equations (1) and (2) can be given the reduced form for the endogenous variables $x$ and $p$ (thought of as vectors now, shown by the omission of index $i$ ). In its reduced form the theory is presented by the price equation only: (Version I)

$$
p=-\pi_{1} s+\pi_{2} d
$$

where evidently

$$
\pi_{1}=\alpha_{1} /\left(\alpha_{2}+\beta_{2}\right) \text { and } \pi_{2}=\beta_{1} /\left(\alpha_{2}+\beta_{2}\right)
$$

The labour categories to be considered are those with differing years of schooling ranging from 8 with intervals of 2 to 16 years. The theory is very simple in that it neglects cross elasticities of demand and supply. This implies that the coefficients found can best be used to estimate the influence of each category's own price on its employment.

\section{New Data from the 1970 U.S.A. Census; Specification of the DEMAND FACTOR}

Contrary to previous U.S.A. population censuses, the 1970 volumes [5] include one in which, for a large number of occupational groups, tables are published showing earnings by education classes and age groups for race and sex groups. In the present study we only took the main occupation categories, leaving out farm managers and workers and combining transport equipment operators with other operators, as was usual in previous censuses.

In order to eliminate the influence of age, unemployment, race and sex we took white males of age 35-54, having worked 50-52 weeks in 1969.

As income for each education category we took earnings for the modal occupational group in the category considered (for the combined group of operators the unweighted average of the two groups just mentioned). The supply factor was taken equal to the numbers of persons in each educational category actually employed in 1969 in specification (i) of both Version I and II of the theory; and equal to estimated numbers employed five years earlier in specification (ii). This estimation was a crude one, based on a comparison of 
1950 and 1970 figures on occupations of all employed white persons; one quarter of the differences in percentages of these employment figures was deducted from the figures of specification (i) in order to obtain (ii) (source: [6]).

The crucial assumption made was that the educational structure of employment within each main occupational group was the same as in 1969. In both specifications the demand factor was estimated by a projection, five years ahead, of employment in each of the educational groups, using the same method as just described for specification (ii) of the supply factor, but assuming a lead instead of a lag. In other words, the desired composition of the labour force as seen by employers was derived from "plans" for the future taking into account changes in occupations to be expected on the basis of the trend 1950-70, but assuming the same educational structure within each of the main occupational groups. This is probably an underestimation of the ensuing demand elasticities, but not a serious one. Summarizing we may say that specification (i) assumes no lag between supply factor and price; specification (ii) a lag of five years of price behind supply; and both specifications assume that the demand factor is based on a projection five years ahead of actual employment in 1969.

\section{The Influence of Lags on Demand and Supply Elasticities for VERSION I OF THE THEORY}

Our method of constructing the demand factor by using the rate of change observed in actual employment of course raises several questions-the more so as the statistical results obtained appear to be remarkably good (cf. Section 4). In a general way, the suspicion may arise that these good results are something built in advance into the theory. More specifically one may wonder whether the lags assumed cannot be "manipulated" so as to obtain some preconceived results. For these reasons, and more particularly, because of the second question raised in this section the role played by the lead of the demand factor with respect to actual employment will be given an explicit form. Indicating the logs of incomes by the vector $p$, those of manpower available by $s$, the rate of growth of $s$ by $g$ and the lead by $t$, the coefficients $\pi_{1}$ and $\pi_{2}$ will be found by solution of the normal equations for the first regression of $p$ on $s$ and $s+\operatorname{tg}$. These equations can be written

$$
\begin{aligned}
(p, s)= & -\pi_{1}\left(s^{2}\right)+\pi_{2}\left\{\left(s^{2}\right)+t(s, g)\right\} \\
(p, s+t g)= & -\pi_{1}\left\{\left(s^{2}\right)+t(s, g)\right\}+\pi_{2}\left\{\left(s^{2}\right)+2 t(s, g)\right\} \\
& +t^{2}\left(g^{2}\right)
\end{aligned}
$$

of which the solutions appear to be:

$$
\pi_{1}=\frac{-(p, s)\left\{(s, g)+t\left(g^{2}\right)\right\}+(p, g)\left\{\left(s^{2}\right)+t(s, g)\right\}}{t\left\{\left(s^{2}\right)\left(g^{2}\right)-(s, g)^{2}\right\}}
$$

and

$$
\pi_{2}=\frac{-(p, s)\left\{\left(s^{2}\right)(s, g)+t(s, g)^{2}\right\}+(p g)\left\{\left(s^{2}\right)^{2}+t\left(s^{2}\right)(s, g)\right\}}{t\left\{\left(s^{2}\right)+t(s, g)\right\}\left\{\left(s^{2}\right)\left(g^{2}\right)-(s, g)^{2}\right\}}
$$

From these formulae we see that there is a clear impact of the lead chosen on the coefficients $\pi$, especially because as a rule the components of $g$ will be small in comparison to those of $s$, implying that the $t$-terms in the numerators will be small in comparison to the terms without $t$. This means that we must have good reasons for the choice of $t$ we make. In specification (i), where prices were supposed not to be lagging behind the demand-supply situation, $t$ comes in as the time employers think ahead in the formulation of the desired manpower structure and it was chosen to be five years. The implication of specification (ii) is that $t$ equals the total of the lag of prices behind the demand-supply situation and of the lead just mentioned. Since the slow reaction of income scales on the market situation is generally recognized, this specification may well be more realistic; it corresponds with a 
value of $t=10$ years. Anyway formulae (7) and (8) enable the reader to make his own choice. From the figures to be discussed in the next section it will be seen that the $\pi$ values are approximately inversely proportional to those of $t$.

\section{Numerical Results for the U.S. Material on 1969 White Males of AgE 35-54: Version I}

The results obtained with the aid of the material described in Section 2 have been summarized in Table I for the simpler version of the theory.

TABLE I

Values of Price Flexibilities $\pi_{1}$ AND $\pi_{2}$ With Regard to Supply and Demand FACTOR, MULTIPLE (R) AND SimPLE CORRElation COEFFICIENTS FOUND fOR SPECIFICATION (i) AND (ii) OF VERSION I OF DEMAND-SUPPLY THEORY

\begin{tabular}{|c|c|c|c|c|c|c|c|c|c|c|c|}
\hline \multirow{3}{*}{$\begin{array}{c}\text { Coefficients } \\
\text { Specification } \\
\text { Value of } t\end{array}$} & \multicolumn{2}{|c|}{$\pi_{1}$} & \multicolumn{2}{|c|}{$\pi_{2}$} & \multicolumn{2}{|c|}{$\mathbf{R}$} & \multicolumn{2}{|c|}{$-r_{p s}$} & \multirow{3}{*}{$\frac{-r_{p d}}{\cdot}$} & \multicolumn{2}{|c|}{$r_{s d}$} \\
\hline & (i) & (ii) & (i) & (ii) & (i) & (ii) & (i) & (ii) & & (i) & (ii) \\
\hline & 5 & 10 & 5 & 10 & 5 & 10 & 5 & 10 & & 5 & 10 \\
\hline $\left.\begin{array}{l}\text { First } \\
\text { Second* } \\
\text { Third* }\end{array}\right\}$ Regression & $\begin{array}{l}+8.5 \\
+10 \\
+10\end{array}$ & $\begin{array}{l}+4.0 \\
+7 \\
+7\end{array}$ & $\begin{array}{l}+8.3 \\
+10 \\
+11\end{array}$ & $\begin{array}{l}+3.8 \\
+7 \\
+7\end{array}$ & 0.96 & 0.945 & 0.76 & 0.76 & 0.72 & 0.998 & 0.997 \\
\hline
\end{tabular}

*Approximate values only.

It is worth mentioning that with simple correlation coefficients of 0.76 and 0.72 only of prices with supply and demand factor, respectively, multiple correlation coefficients well above 0.9 are found. It is also striking that with as high an intercorrelation as exists between the two explanatory variables $s$ and $d$ the margins of error as shown by the second and third regressions (following Frisch's "bunch map" method [2]) are not destructive.

The first regression equation shows the almost inverse proportionality between $t$ and $\pi$ values. Whoever would opt for longer lags would obtain $\pi_{1}=+2$ for a twenty-year lagcum-lead or $\pi_{1}=+1$ for a forty-year one. This means that our findings show an elasticity of demand of all labour categories considered of -0.25 if one adheres to a ten-year and -0.5 for a twenty-year lag-cum-lead which seem to be the most likely values of $t$. This adds another case of rather low demand elasticities to the ones I collected elsewhere [3], drawing on work by Fallon and Layard [1] and on my own interpretation of material shown by Mrs. Ullman-Chiswick and by Dougherty. In the article just quoted I presented a demandsupply scheme similar to the one discussed in the present article. The demand factor was not constructed, however, by a forward projection of Mexican employment but by assuming the Japanese industrial structure to be the one aimed at by Mexican employers. (The industrial structure was used as against the occupational structure in the present article.) In order to throw some light on the choice of $t$ we can state that the per capita GNP ratio of Japan to Mexico was 2.86 in 1970 and that it took Japan 11.5 years to grow at that rate, whereas the Mexican growth rate requires 29 years to bridge the ratio. One might conclude that choices for $t$ between 10 and 30 years seem to make sense.

\section{Numerical RESUltS FOR THE U.S.A.: VERSION II OF THE THEORY}

Turning to Version II of the theory, we see from equations (4) that the four coefficients $\alpha$ and $\beta$ can only be estimated if either supplementary assumptions are made or supplementary information is available. Here I only will repeat the treatment I applied to the Mexican material just mentioned [3]. One additional assumption was made, namely that $\alpha_{1}=1$ : the number of those offering themselves for employment are proportional to the numbers available in each educational category. The additional information is taken 
from Mrs. Chiswick's study, [4] where she finds $\alpha_{2}=-1.25$, adding my own tentative interpretation of her results which yields $\alpha_{2}=0.17$. Since $\alpha_{2}+\beta_{2}=1 / \pi_{1}=0.25$, this leaves us with $\beta_{1}=\pi_{2}\left(\alpha_{2}+\beta_{2}\right)=0.95$ and $\beta_{2}=0.25-\alpha_{2}$. For the two alternative values of $\alpha_{2}$ mentioned this implies for $\beta_{2}$ the value of 1.50 (following Mrs. Chiswick) or 0.08 (following my alternative interpretation). Had we taken $\pi_{1}=8.5$ (that is, $t=5$ ), we would have found $\beta_{1}=1.0$ and $\beta_{2}=1.13$ or -0.5 . For $t=20$, the results would have been $\beta_{1}=1.0$, and $\boldsymbol{\beta}_{2}=1.3$ or -0.1 . Again the conclusion may be drawn that the elasticity of demand for labour is of the order of -1 or less.

\section{REFERENCES}

[1] Fallon, P. R. and Layard, P. R. G., "Capital-Skill Complementarity, Income Distribution and Output Accounting", forthcoming (Higher Education Unit, London School of Economics and Political Science).

[2] Frisch, R. Confluence Analysis, Oslo 1934.

[3] Tinbergen, J., "Substitution of Academically Trained by Other Manpower", forthcoming.

[4] Ullman, C., "The Growth of Professional Occupation in the American Labor Force: 1900-1963" (World Bank summary of unpublished thesis, Columbia University, 1972).

[5] U.S. Bureau of the Census, 1970 Census of Population, Earnings by Occupation and Education, Washington DC, 1973, PC(2)-8B.

[6] U.S.A.: Executive Office of the President, Office of Management and Budget: Social Indicators 1973, Washington DC, 1973. 
Copyright of Review of Income \& Wealth is the property of Blackwell Publishing Limited. The copyright in an individual article may be maintained by the author in certain cases. Content may not be copied or emailed to multiple sites or posted to a listserv without the copyright holder's express written permission. However, users may print, download, or email articles for individual use. 